\title{
Facilitating Concept Map Analysis: Generating and Evaluating Representative General Chemistry Concept Maps with a Novel Use of Image J, Gephi, JPathfinder, and R
}

\author{
Emily Z. Huie ${ }^{1}$ (D), Risa Uday Sathe ${ }^{1}$ (D) , Anish Wadhwa ${ }^{1}$ (D), Efrain Vasquez Santos ${ }^{1}$ (D), \\ Ozcan Gulacar ${ }^{1 *}$ \\ ${ }^{1}$ Chemistry, University of California, USA
}

Received 1 June 2021 - Accepted 2 December 2021

\begin{abstract}
Concept maps are powerful tools used to reveal challenges in students' learning. However, their use introduces complexities when a large group of students' conceptualizations need to be examined. In this study, concept maps of 344 general chemistry students were analyzed after grouping them based on achievement in chemistry, math proficiency, and gender. The analysis was also expanded with the consideration of eccentricity values and the extended chemistry triplet. Although some similarities exist between the map of high-achieving students in chemistry and that of high-performing students in the Mathematics Placement Test (MPT), the calculated eccentricity values show interesting variations. On the other hand, the analysis of the map of the low-performing students in MPT and that of low-achieving students in chemistry revealed no clear patterns of symbolic, macroscopic, and submicroscopic terms. Practical suggestions were included to increase the use of representative maps in different assessment and teaching scenarios.
\end{abstract}

Keywords: chemistry education, assessment, constructivism, concept maps, chemistry triplet

\section{INTRODUCTION}

Students pursuing STEM degrees are often required to take chemistry courses to build a foundation for developing a deeper understanding of topics presented in other science courses (Cohen \& Kelly, 2019; Schreiber, 1991). Chemistry is often regarded as a difficult subject due to its abstract concepts and heavy math applications (Boujaoude \& Attieh, 2008; Johnston et al., 2016; Preininger, 2017). Therefore, it is essential to find effective and pragmatic methods chemistry educators can employ to determine what makes chemistry challenging, evaluate sources of students' learning difficulties, and equip students with tools to learn and understand chemistry concepts more effectively (Boujaoude \& Attieh, 2008; Luxford \& Holme, 2015).

Studies on information processing indicate that meaning is assigned to introduced concepts by using the brain's ability to identify unique patterns between topics and integrate them into long-term memory to create dynamic mental models, which are also defined as knowledge structures (Bada, 2015; Caine \& Caine, 2006; Yeh, 2004). There is consensus that concept maps, a graphical network representation of an individual's knowledge structure, are an effective tool in demonstrating how students form connections between topics. (Talbert et al., 2020; Van Zele et al., 2004). Moreover, concept maps serve as an x-ray of the mind and enable researchers and educators to gain insight into the nature of an individual's knowledge structure and overall degree of understanding (Burrows \& Mooring, 2015; Kaya, 2008; Nicoll et al., 2001; Schreiber, 1991; Von Der Heidt, 2015). Concept maps were also found to be an effective form of assessment because students are encouraged to draw relationships between the concepts they learn (Talbert et al., 2020). When it comes to developing ways to measure and assess student understanding, finding valid and reliable methods to complete such task is a prevailing challenge amongst educators. For instance, although they are the most common type of assessment method, creating effective multiple-choice exams that reveal the student's

(c) 2022 by the authors; licensee Modestum. This article is an open access article distributed under the terms and conditions of the Creative Commons Attribution License (http://creativecommons.org/licenses/by/4.0/). 


\section{Contribution to the literature}

- In this study, a unique combination of the Image J, R, and Gephi was utilized to convert many concept maps into single representative knowledge structures to facilitate concept map analysis of large groups.

- Concept maps are traditionally studied by determining cues through qualitative investigation. Our methodology would help those who would like to take a more quantitative approach and examine any number of concept maps at once.

- In the literature, there is a gap between Johnstone's chemistry triplet and knowledge structures. This study examined the influence of students' representation of knowledge on the organization of their chemistry structures.

reasoning behind a particular answer is considerably difficult task (Neiles, 2014). Even tests with open-ended questions that are utilized to better analyze students' conceptual understanding also fall short in revealing full details of students' knowledge structures (Kaya, 2008; Neiles, 2014; Yaman \& Ayas, 2015). For these reasons, educators are encouraged to consider other assessment methods that target conceptual understanding to measure progress (Talbert et al., 2020). By using concept maps as a tool for assessment, educators can investigate how students understand introduced concepts and assist with remediation and elimination of alternative conceptions (commonly referred to as misconceptions) (Pirnay-Dummer, 2014; Schreiber, 1991; Trumpower et al., 2014).

Due to their importance as an assessment tool, it is crucial to develop efficient mechanisms that objectively analyze concept maps in order to truly reveal the students' knowledge structure. Throughout the literature, there is no consensus on the most effective way to analyze a concept map. Traditionally, concept maps are analyzed individually. When a researcher uses a qualitative approach to study the individual concepts maps, interviews or classifying the type of concept map organization are typically used (Heron et al., 2018; Schreiber, 1991). While such qualitative approaches provide some insight on students' learning, the associated interviews were determined to impact students' pure thinking and result in fabrication of some interpretations that are not truly representative of their conceptualization (Van Zele et al., 2004). In order to obtain objective measurements of a student's conceptualization that would enable researchers to use concept maps for assessment, researchers have employed quantitative methods where the quality of students' maps was evaluated by a scoring system in which the number of valid connections were counted (Kaya, 2008; Kibar et al., 2013; Van Zele et al., 2004). Although this technique provides a quantitative form of assessment, due to the researcher's assumption of what is deemed to be a valid connection, there is still some level of subjectivity that influences the data. (Neiles, 2014; Yaman \& Ayas, 2015). Additionally, the aforementioned approaches for analyzing concept maps are traditionally on an individual scale, and while they help illuminate student understanding, such processes would become quite challenging if there are hundreds of maps to analyze and the goal is to evaluate an overall group. There have been efforts by researchers to create a group level concept map by counting frequency of terms that appeared in each individual map and then placing the terms that occurred the most into the representative map (Krabbe, 2014). While a representative map was generated, this process required each map to be individually analyzed which may become quite tedious when there are many of maps to analyze. In this study, the novel use of $\mathrm{R}$ together with ImageJ, Gephi, and JPathfinder can ease the process of group level analysis and provide researchers and educators an objective method to generate a representative concept map that is a depiction of a group's knowledge structure.

In order to further understand how students construct their knowledge in chemistry, researchers have categorized concepts and terms into three representational levels of chemistry - submicroscopic, macroscopic, and symbolic - commonly referred to as the chemistry triplet, and its extension, process (Johnstone, 1991). The submicroscopic level is related to concepts at the particle level such as atoms and bonding and are often used to explain macroscopic phenomena (Becker et al., 2015; Gulacar et al., 2019; Taber, 2013; Talanquer, 2011a; Yaman \& Ayas, 2015). The macroscopic level represents tangible quantities that can either be measured or quantities that cannot be measured directly, but can be calculated, such as energy (Becker et al., 2015; Gulacar et al., 2019; Yaman \& Ayas, 2015). The symbolic level illustrates the synthesis of the submicroscopic and the macroscopic levels and represents the overall changes of chemical substances typically expressed through equations and formulae (Becker et al., 2015; Dori \& Sasson, 2008; Gulacar et al., 2019). Dori and Hameiri (2003) proposed a fourth representational level of chemistry referred to as the process domain that represents the changes that occur when substances react with one another and serves as a connection linking the representational levels in chemistry triplet. These four representational levels of chemistry, referred to as the extended chemistry triplet in this study, provide researchers another dimension to understand how students conceptualize chemistry. Utilizing the extended 
chemistry triplet is important because it was found that knowledge based on alternative conceptions of chemistry concepts and of the relationship between the representational levels can impede their learning process and ability to make valid connections between terms (Talanquer, 2011a; Yaman \& Ayas, 2015). As a result, this lack of adequate understanding of how each representational level corresponds with one another could lead to greater difficulty in solving chemistry problems (Taber, 2013). For these reasons, it is necessary to develop a method to evaluate any patterns of how students relate each level to each other. The representative maps generated in this study were used to identify patterns of how the overall group organizes the extended chemistry triplet in their knowledge structure. There are few studies that combine knowledge structures and the chemistry triplet (Gulacar et al., 2020; Yaman \& Ayas, 2015). The synthesis of the extended chemistry triplet and representative maps generated in this study may help provide chemistry educators a more robust understanding of their students' chemistry knowledge.

The purpose of this study is to analyze concept maps generated by a large group of undergraduate students at the end of the General Chemistry series and create representative maps researchers can use for as a reference during concept map evaluation. The investigation is focused on analyzing concept maps by using a novel synthesis of the $\mathrm{R}$ and Gephi, illuminating the correlation between the structure of concept maps and students' achievement in chemistry and math, enlightening the role of gender in concept map construction, and identifying the connections between macroscopic, submicroscopic, and symbolic, and process representational levels of chemical knowledge.

\section{Research Questions}

This study was guided by three questions:

1. How are high- and low-achieving chemistry students' knowledge structures different?

2. How does the performance on the math placement test relate to chemistry knowledge structures?

3. How do male and female students organize their knowledge structures?

\section{METHODOLOGY}

\section{Participants and Design}

Following IRB approval, students enrolled in the last course in the General Chemistry series were invited to participate in this study. A total of 344 (246 females; 98 male) general chemistry students volunteered to help examine potential factors influencing concept map constructions. The participants were instructed to organize a concept map of major chemistry concepts and terms covered in the General Chemistry series. In order to facilitate the data collection, an online concept map construction site, Bubbl.us, was utilized. The students were instructed to put concepts they assumed being related closer together and move unrelated terms farther apart thereby forming clusters of related terms. To identify the most important concepts covered in the General Chemistry series, a tentative list of concepts was generated by two chemistry professors, two chemistry graduate students, and several undergraduate students. The list was refined and finalized by examining related published studies (Earl, 2007; Luxford \& Holme, 2015; Murphy et al., 2012). The final list included seventeen major chemistry terms, which are: Acid/Base; Atom; Bonding; Change; Coordination Chemistry; Electrochemistry; Energy; Equilibrium; Forces; Kinetics; Matter; Periodic Trends; Reactions; Solubility; Spontaneity; Stoichiometry; and Structure.

In addition, the information on students' demographics, chemistry grades, and Mathematics Placement Test (MPT) scores were also gathered. To study if chemistry achievement in the course explains the differences between concept maps, students' letter grades for each course in the General Chemistry series were converted into the scale of 4.0 and their average grade was used to represent their performance. Once the students were ranked based on their average grade in a descending order, it was determined that there were 28 students with a 4.0, who were categorized as highachieving students and 28 students with the range of 2.02.333 were categorized as low achieving students and selected from the bottom of the ranking list (Andrews \& Andrews, 1979; Johnston et al., 2016; Ralph \& Lewis, 2018). The relationship between students' performance on the MPT and variations on concept maps were also investigated. For determining the impact of math proficiency on how students organize their concept maps, the MPT scores were utilized. The students were first ranked in order of increasing MPT scores and then top 30 participants with a score of 57-60 and bottom 30 with a score of 22-34 were selected. Finally, in order to explore the potential differences between female and male students, a random sample of 30 males and 30 females were selected.

\section{Data Analysis}

In order to overcome the aforementioned challenges with concept map analysis and working with individual maps, the authors decided to take a quantitative approach by using proximity data, the distances between all the nodes present on concept maps. The measurements were done with Fiji Image J, a program utilized frequently in biology to analyze cell images. After the completion of measurements on individual concept maps, the average values were determined for each group examined in the study and these averages were used to generate the representative concept maps. To create 3D concept maps, $\mathrm{R}$, was used to create dim 
values. $\mathrm{R}$ uses Multidimensional Scaling (MDS), which is a set of mathematical techniques that enable a researcher to uncover the "hidden structure" of data bases (Kruskal, 1978). The analysis plots concepts as points in multidimensional Euclidean space so that the distances between concepts represent the strength of the association (similarity) between terms (Wilson, 1996). In order to further analyze these concept maps, clusters were identified to illustrate which terms students view as closely related. Across the literature it is mentioned that finding an objective approach that justifies why one term belongs in a specific cluster, not the other, or both is difficult. To ameliorate this issue, clusters were defined by inputting the calculated averages of the distances into a Hierarchical Clustering Analysis code in R (Kodali, 2016). Not only does this enhance objectivity, it provides researchers an effective method to identify clusters. R uses Agglomerative Clustering (AGNES), a code that uses proximity data to place terms that are most similar into a cluster. These clusters are then illustrated through a scatter plot which are included alongside the representative maps for reference (Kodali, 2016).

Gephi, a network generating program, was used to create visually rich concept maps that represent the nature of each group's level of conceptualization. Although clusters were determined based on a reliable algorithm, it is important to note that it is almost impossible to tell which terms are truly central to each concept map. In order to further evaluate the knowledge structures determined in this study, it was essential to identify which chemistry concepts are deemed as most important, or central, to students when they relate chemistry concepts. Researchers could not use Gephi or $\mathrm{R}$ to reveal central concepts; therefore, JPathfinder was used to determine eccentricity values, a centrality measure that reveals central terms on each group's concept map. The eccentricity value is calculated by determining the maximum number of connections a node makes with other nodes within the network. This value can be used to illustrate the hierarchy of terms or concepts a group views as important. The lower the eccentricity value, the more closely connected or central the concept is to other concepts. Inversely, terms with higher eccentricity values are deemed to be not as connected to other concepts, in other words not as central.

In addition to utilizing the eccentricity values, the extended chemistry triplet was considered in the analysis of clusters. The seventeen terms used in this study were classified using Becker's classification (2015) of each level based on inductive analysis, as well as the same classification schema determined by a group of chemistry professors and graduate and undergraduate students (Gulacar et al., 2019). Through this process, it has been found that chemistry terms can be classified with more than one representational level of chemistry (Gulacar et al., 2019, 2020).

\section{RESULTS AND DISCUSSION}

The use of $\mathrm{R}$ and Gephi successfully produced representative maps that enabled the researchers to identify the relationship between chemistry achievement and chemistry knowledge structure, gain insight into how prior knowledge in math may correlate with chemistry concept maps, and determine if gender influences concept map creation. A discussion on the interaction between the extended chemistry triplet and concept map construction is introduced to provide researchers a deeper insight into students' knowledge structures.

\section{Comparing Concept Maps of High- and Low- Achieving Students in Chemistry}

The first objective of our investigation was to identify and evaluate how high- and low-achieving students in chemistry construct their concept maps. As seen in the Figure 1, there are two clusters in high-achieving and three clusters in the low-achieving group. In the highachieving chemistry students' map, the red cluster may be considered a super-cluster because it is larger than any of the other clusters that was observed in this study.

This super cluster may support the interpretation that high-achieving students have developed a more coherent understanding of the interaction between different concepts. It is, however, difficult to claim definitively if supercluster is indicative of higher achievement in chemistry without an expert map (Kaya, 2008; Schreiber, 1991). Atom, matter, coordination chemistry, and periodic trends are a part of the same cluster in both high- and low-achieving students' maps, but in the high-achieving group, bonding and kinetics are isolated concepts. Bonding and kinetics are classified as isolated due to the algorithm in R. When observing the low-achieving map, no isolated concepts were found. To some extent, the analysis of these representative maps can help researchers explain the differences in success between the two groups and brings attention to alternative conceptions in their knowledge structure. For example, in the low-achieving chemistry map, the term kinetics is clustered with energy and forces. It is likely that low-achieving students have the association of kinetics with kinetic energy, not the rate or mechanism of a reaction, that led to the placement of it near forces and energy. These misconnections in their knowledge structures could lead to incorrect interpretation of questions and result in problem solving difficulties with kinetics related problems. Chi et al. (1981) determined that students with less experience and understanding of material often utilize surface features of questions and, as a result, fail to identify true nature of those questions. Pólya (1945) in his famous problem-solving strategy, 


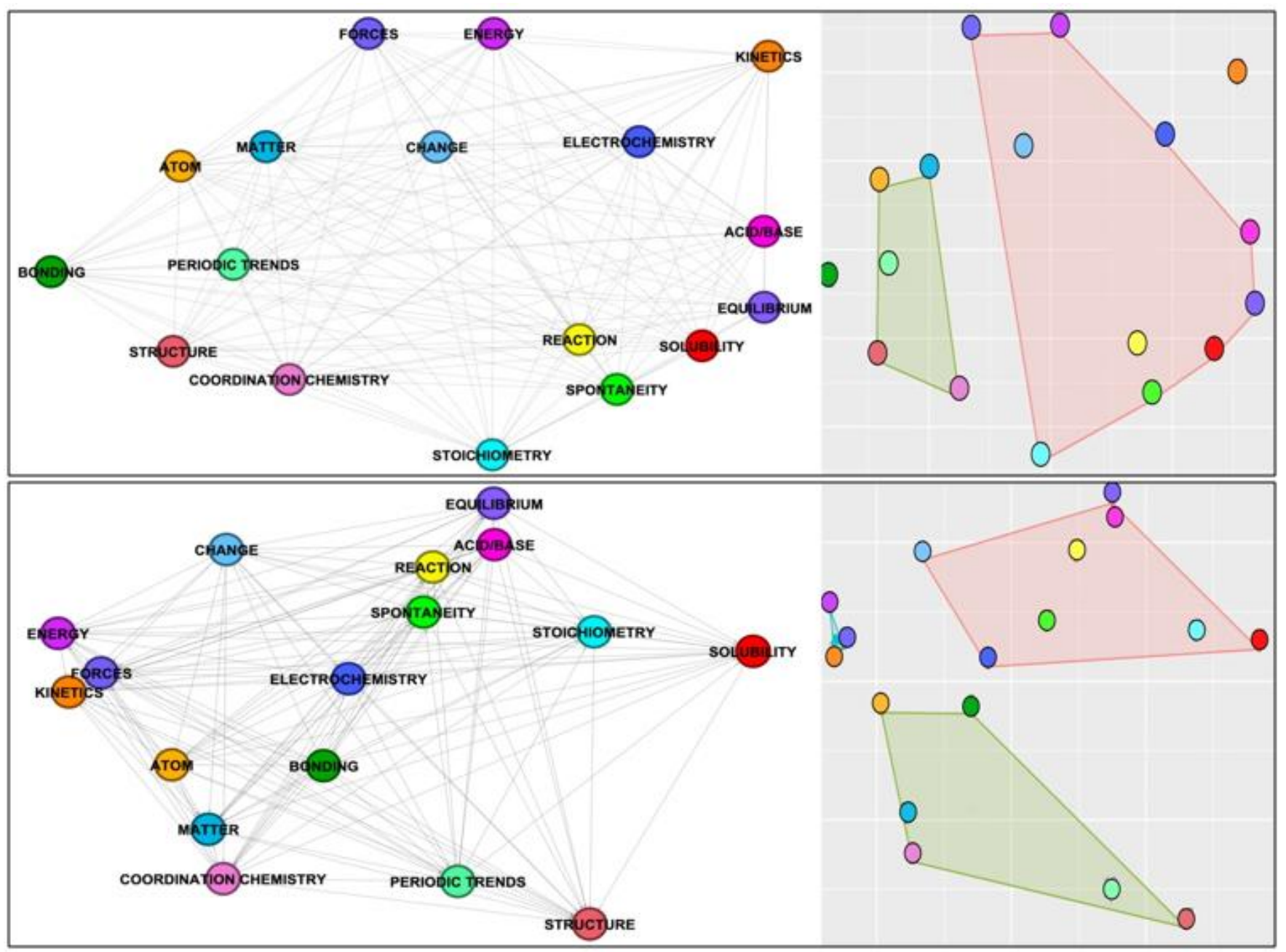

Figure 1. Knowledge structures of high-achieving (top) and low-achieving students (bottom) in chemistry

understanding the question is listed as the first step. Without clarifying the meaning behind the question, achieving that goal will be less possible with misconnections or alternative conceptions in the knowledge system (de Astudillo \& Niaz, 1996; Sharara, 2011; Smith \& Bermea, 2012).

The central concepts of the high- and low-achieving in chemistry knowledge structures illuminate further differences between these two groups. When the eccentricity values of each group were examined on Table 1, it was noted that the central terms for highachieving students in chemistry were bonding and stoichiometry, whereas the low-achieving students have atom and change as terms central to their knowledge structure.

In General Chemistry, there is a great emphasis on how matter changes, and students are expected to carry out stoichiometry calculations involving mass, mole, or volume changes, which is widely accepted as one of the most challenging topics covered in introductory chemistry courses (Cotes \& Cotuá, 2014; Gulacar et al., 2014). Bonding is also a critical topic covered and visited several times throughout the general chemistry curriculum - its understanding is essential for anyone to become successful in explaining changes in chemical reactions (Luxford \& Bretz, 2014; Murphy et al., 2012; Vrabec \& Prokša, 2016). These terms bonding and

Table 1. Eccentricity values of terms for high- and low-achieving students in chemistry

\begin{tabular}{|c|c|c|c|c|c|c|c|c|c|c|c|c|c|c|c|c|}
\hline 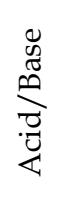 & 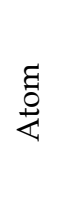 & 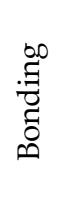 & $\begin{array}{l}\mathscr{\Xi} \\
\underset{\Xi}{\Xi} \\
\text { U }\end{array}$ & 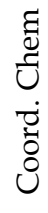 & 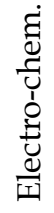 & 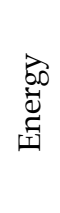 & 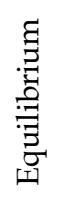 & $\begin{array}{l}\text { 巳 } \\
\stackrel{0}{0} \\
\text { I }\end{array}$ & 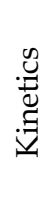 & 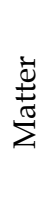 & 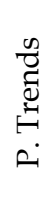 & 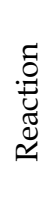 & 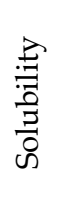 & 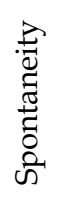 & 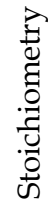 & 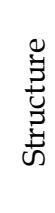 \\
\hline 8 & 6 & $5^{*}$ & 7 & 7 & 9 & 8 & 7 & 7 & 9 & 7 & 7 & 6 & 9 & 8 & 5* & 6 \\
\hline 6 & $4^{*}$ & 5 & $4^{*}$ & 6 & 5 & 5 & 5 & 7 & 6 & 5 & 7 & 6 & 6 & 7 & 7 & 6 \\
\hline
\end{tabular}

* Central terms are indicated by an asterisk 
stoichiometry are critical for solving problems that require a higher order thinking skill (Paideya \& Sookrajh, 2010; Ralph \& Lewis, 2018). However, one can argue that lowachieving students' second central term, atom, as a standalone term does not require a higher-order thinking to master it, even though it is defined as the building block of matter and frequently referenced in General Chemistry (Luxford \& Holme, 2015).

It is also important to identify which terms deviate furthest from the center in each group's knowledge structure because they may reveal areas where students require clarification. It is argued that the most deviated terms are least connected to the knowledge system; therefore, possibly less understood (Ekmekci et al., 2018; Gulacar et al., 2015). For high-achieving students, these terms were electrochemistry, kinetics, and solubility each with an eccentricity value of 9 . It should be noted that two out of these three terms, kinetics and electrochemistry, are covered in the last course of the General Chemistry series in a quarter system. The survey in this study was administered after a few weeks these topics were introduced in the class. It is possible that students did not have enough time to practice and make connections between these newly learned concepts and their preexisting knowledge (van Kesteren et al., 2018). As for the low-achieving chemistry students, the picture was different - excluding periodic trends, all other concepts that deviated most from the center, forces, spontaneity, and stoichiometry, were taught in the second part of the General Chemistry series. In this instance, it is possible that this group had low engagement with making connections or had ineffective study strategies (Tait \& Entwistle, 1996). Finally, it is interesting to note that the term stoichiometry is a central term for high achieving students but deviated the most from the center in the low-achieving students' map. Due to the challenging nature of stoichiometry, this finding may reveal that low-achieving students require more support when learning this topic. In essence, stoichiometry is a critical topic that separates high- and low-achieving students' success in chemistry (Coll et al., 2006).

While these differences observed in the clusters and eccentricity values provided valuable insight into understanding the variations in high- and low-achieving students' map construction, it was realized that there is an absence of studies involving the knowledge structures and cluster analysis in science education resulted in difficulties in analysis. Therefore, the extended chemistry triplet was considered to aid in interpretation of overall trends. Each of the three representational levels of chemistry, macroscopic, submicroscopic, symbolic, and its extension, the process domain, were evaluated on each representative knowledge structure. The seventeen terms used in this study were classified using Becker's (2015) classification of each level based on inductive analysis, as well as the same classification schema determined in a study completed by Gulacar et al. (2019) in which a group of chemistry professors and students that take the course categorized these terms based on the wide range of response words gathered in the Word Association Tests and how these concepts were introduced in the class. Through this process, it has been found that chemistry concepts can be classified with more than one representational level of chemistry (Gulacar et al., 2015, 2019). According to Johnstone (1991), chemistry students may face difficulty when solving chemistry problems because they do not connect concepts and terms at more than one representational level (Johnstone, 1991). Those that exhibit higher performance in chemistry have a greater ability to relate concepts with one another (Schreiber, 1991). Moreover, a student relating terms to more than one representational level may indicate a higher level of understanding of chemistry concepts and terms (Gulacar et al., 2020; Talanquer, 2011b). Table 2 is a list of all terms with their extended chemistry triplet classifications.

In order to analyze students' structures with this new lens, the maps were regenerated by marking each term with a symbol that corresponds with its classification on each concept map (see Figure 2, Figure 4, and Figure 6). For terms that have more than one extended chemistry triplet categorization, the categorization that the term is more associated to was indicated by a larger symbol.

As seen in Figure 2, on the high-achieving map, submicroscopic terms group together in the left portion

Table 2. Categorization of terms with correlating extended chemistry triplet

\begin{tabular}{|c|c|c|c|c|c|}
\hline Term & Classification & Term & Classification & Term & Classification \\
\hline Atom & Submicroscopic & Stoichiometry & Symbolic & Solubility & Macroscopic \\
\hline Bonding & Submicroscopic & Structure & Submicroscopic & Electrochemistry & $\begin{array}{l}\text { Macroscopic, } \\
\text { Symbolic }\end{array}$ \\
\hline Energy & $\begin{array}{l}\text { Macroscopic, } \\
\text { Submicroscopic }\end{array}$ & Reaction & $\begin{array}{c}\text { Process, } \\
\text { Macroscopic }\end{array}$ & Kinetics & $\begin{array}{c}\text { Macroscopic, } \\
\text { Symbolic }\end{array}$ \\
\hline Matter & Macroscopic & Equilibrium & Process, Macroscopic & $\begin{array}{l}\text { Coordination } \\
\text { Chemistry }\end{array}$ & $\begin{array}{l}\text { Symbolic, } \\
\text { Submicroscopic }\end{array}$ \\
\hline Change & $\begin{array}{c}\text { Macroscopic, } \\
\text { Process }\end{array}$ & Spontaneity & Macroscopic & Periodic Trends & $\begin{array}{c}\text { Symbolic, } \\
\text { Submicroscopic }\end{array}$ \\
\hline Forces & $\begin{array}{c}\text { Submicroscopic, } \\
\text { Macroscopic }\end{array}$ & Acid/Base & $\begin{array}{l}\text { Submicroscopic, } \\
\text { Macroscopic }\end{array}$ & & \\
\hline
\end{tabular}



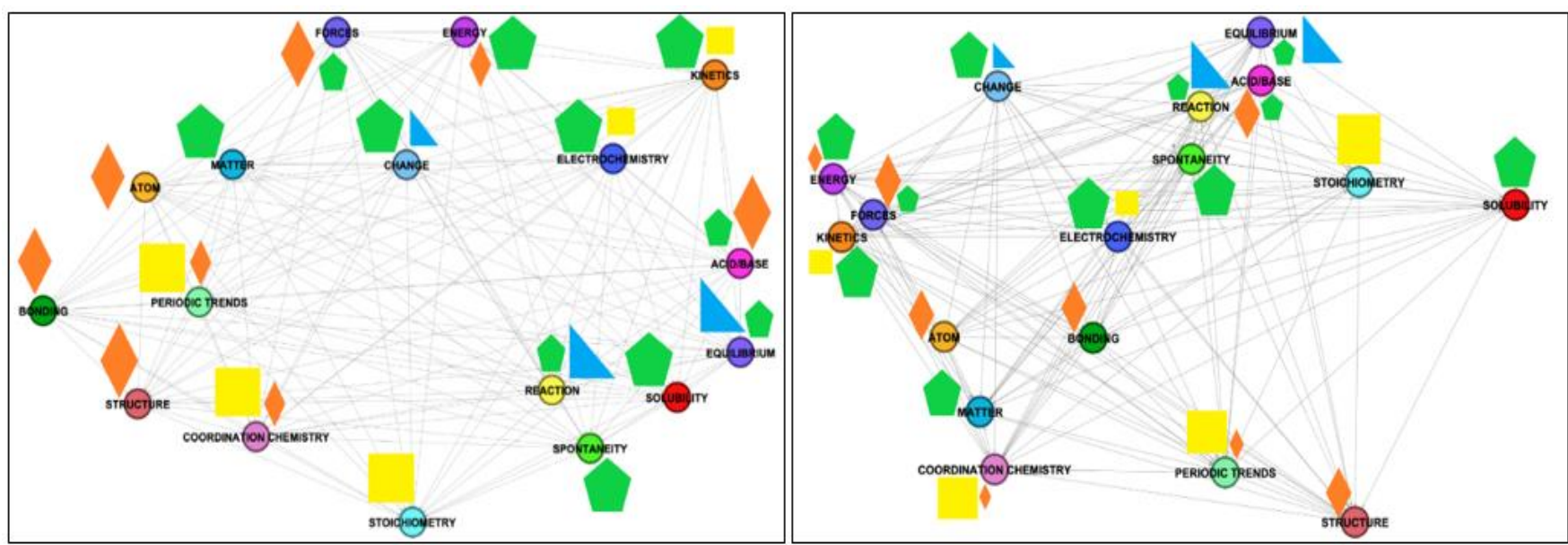

Figure 2. Knowledge structures with chemistry triplet of high-achieving (left) and low-achieving students (right). Meaning of symbols: Pentagon-macroscopic, diamond-submicroscopic, square- symbolic, triangle- process

of the structure where acid base is the only submicroscopic term on the left side. Macroscopic terms aggregate on the right side of the structure where matter is the only macroscopic term on the right side. The symbolic terms, periodic trends, coordination chemistry, and stoichiometry are close in proximity and electrochemistry and kinetics which are secondarily symbolic are close in proximity. Additionally, process terms, reaction and equilibrium are in close relations with one another and are in the same cluster depicted by $\mathrm{R}$. In this knowledge structure, there are clear groupings of terms that fall within the same representational level of chemistry classification. This may indicate that high-achieving students tend to group terms in their minds based on their predominant representational levels of chemistry. According to Johnstone (1991), chemistry students may face difficulty when solving chemistry problems because they do not connect concepts and terms at more than one representational level. Those that exhibit higher performance in chemistry have a greater ability to relate concepts with one another (Schreiber, 1991). Moreover, a student relating terms to more than one representational level may indicate a higher level of understanding of chemistry concepts and terms. For low-achieving students, there is less of a distinct grouping pattern. For instance, submicroscopic terms are mostly integrated with other terms not forming a clear pattern as visualized in the high-achieving map. This may reveal that low-performing students have difficulty relating and understanding terms with their respective representational levels of chemistry and therefore, may have difficulty with understanding the relationships between the terms themselves (Johnstone, 1991; Taber, 2013).

\section{Investigating the Role of Math Proficiency in Concept Maps}

Researchers found that proficiency in math is found to be a good predictor of students' success in STEM courses (Andrews \& Andrews, 1979; Johnston et al., 2016; Williamson et al., 2020). The second objective of our investigation was to provide insight on the correlation between math proficiency and the understanding of chemistry concepts. The representtative maps may reveal the correlation between prior knowledge in mathematics and the structure of chemistry concept maps (Andrews \& Andrews, 1979). In the high-MPT map there are three clusters whereas the low-MPT map has four clusters (Figure 3).

It is important to note that in the high-MPT map, coordination chemistry is an isolated concept whereas in the low-MPT map, there are no isolated concepts. At first look, the high-MPT and low-MPT maps seem quite different, however upon further analysis, they both place most terms within the same clusters. The terms that are clustered differently include coordination chemistry, change, kinetics, and forces.

Similar to the map of low-achieving students in chemistry, the High MPT concept map also has kinetics and energy within the same cluster. This may be due to the possibility that those that exhibit higher levels of algorithmic competence consider the more superficial aspects of concepts without considering the deeper meaning they carry (Chi et al., 1981). While cluster analysis revealed some differences between the maps, the central concepts for each group reveals even greater differences between the two groups (see Table 3). For high-scoring students on the mathematics placement exam, central terms were energy and kinetics, where atom was determined as the central concept for the lowscoring students in mathematics. Notably, atom was the central concept on the map of low-achieving students in chemistry as well. The terms with the greatest deviation from the center for high-scoring students were matter, periodic trends, stoichiometry, and solubility with an eccentricity value of nine. For low-scoring students, acidbase is the term with the greatest deviation from the center with an eccentricity value of ten. In addition, there are five terms, equilibrium, forces, solubility, spontaneity, 


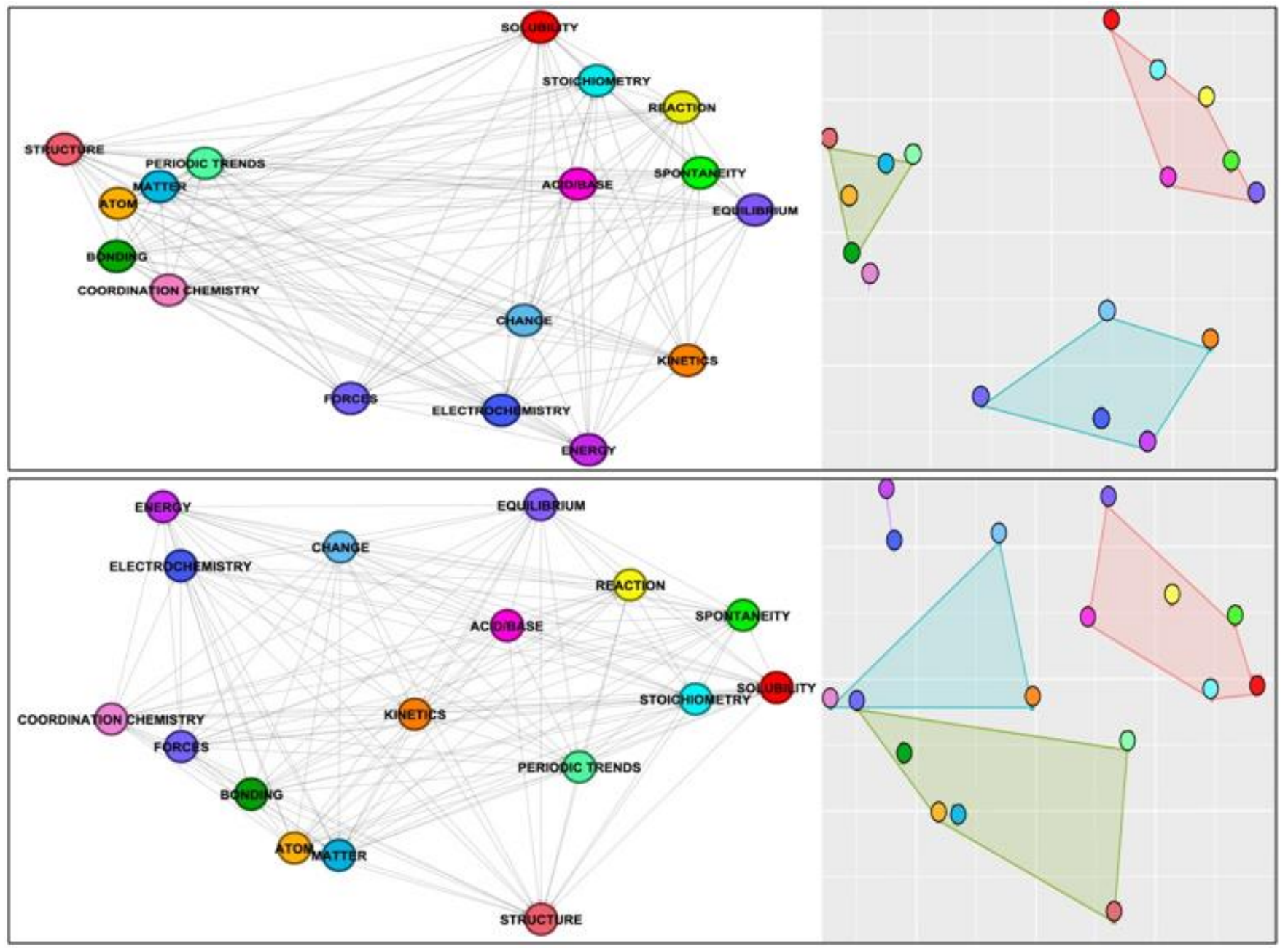

Figure 3. Knowledge structures of students with high MPT scores (top) and low MPT scores (bottom)

Table 3. Eccentricity values of terms for high- and low-MPT groups

\begin{tabular}{|c|c|c|c|c|c|c|c|c|c|c|c|c|c|c|c|}
\hline 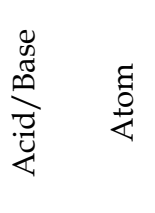 & 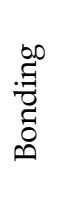 & 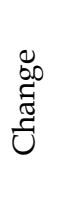 & 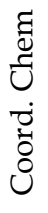 & 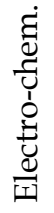 & $\begin{array}{l}\overrightarrow{b 0} \\
\overrightarrow{0} \\
\overrightarrow{|c|}\end{array}$ & 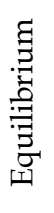 & 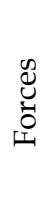 & $\begin{array}{l}\stackrel{\mathscr{U}}{\stackrel{D}{U}} \\
\stackrel{\Xi}{\Xi}\end{array}$ & 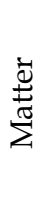 & 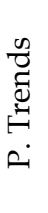 & 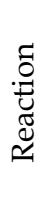 & $\begin{array}{l}\stackrel{3}{0} \\
: 3 \\
3 \\
0 \\
0 \\
\infty\end{array}$ & 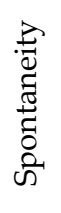 & 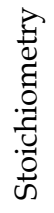 & 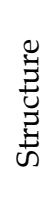 \\
\hline 8 & 7 & 6 & 8 & 6 & $5^{*}$ & 6 & 6 & $5^{*}$ & 9 & 9 & 8 & 9 & 7 & 9 & 8 \\
\hline $5^{*}$ & 6 & 8 & 7 & 8 & 7 & 9 & 9 & 8 & 6 & 7 & 8 & 9 & 9 & 9 & 6 \\
\hline
\end{tabular}

* Central terms are indicated by an asterisk

stoichiometry with a close eccentricity value of nine. There are certainly more terms in low MPT maps that are considered edge terms, which could be a sign for an undeveloped knowledge structure and poor conceptual understanding (Gadner \& Ohnesorge, 2004; Ørom, 2003). However, it is not possible to determine exactly how much this structure is deviated from the ideal organization without an expert map (Ambrose et al., 2010).

Due to the observed correlation between math proficiency and achievement in chemistry, it is often brought to question to what extent the level of proficiency in math influences understanding of chemistry topics (Andrews \& Andrews, 1979; Ralph \&
Lewis, 2018; Williamson et al., 2020). It was found that student with low Math SAT scores struggled with all topics in general chemistry, and the topics which were mathematical in nature were especially difficult for these students (Ralph \& Lewis, 2018; Talbert et al., 2020; Williamson et al., 2020). Atom is defined as a more conceptual topic (Van Zele et al., 2004), which can provide insight as to why atom is the central term for the low-MPT concept map. Kinetics and energy are topics that are more mathematical which can also provide insight into why kinetics and energy are central terms for the highMPT map. Due to the assertion that high proficiency in math is related to success in chemistry, one may expect that the high-achieving chemistry map and high-MPT 


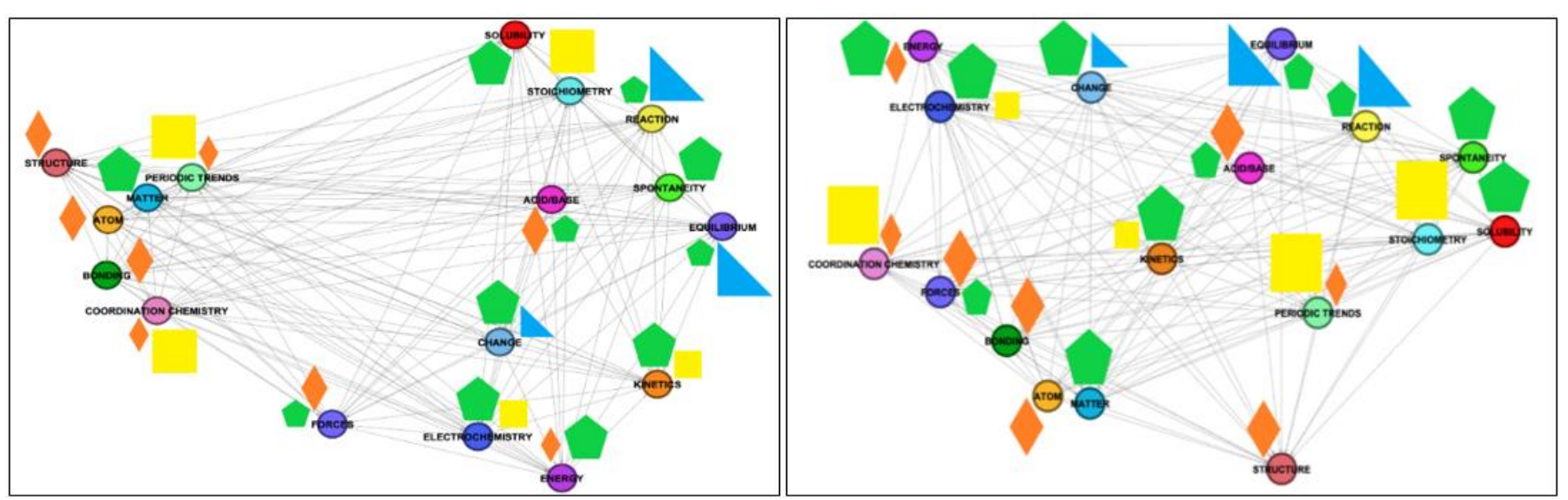

Figure 4. Knowledge structures with chemistry triplet of students with high MPT scores (left) and low MPT scores (right). Meaning of symbols: Pentagon-macroscopic, diamond-submicroscopic, square- symbolic, triangle- process

map would be similar. However, while the eccentricity values and clusters for some terms of the high-achieving chemistry map are similar to those of the high-MPT map, there are multiple terms that do not align, such as equilibrium, kinetics, and acid/base which have heavy math applications (Johnston et al., 2016). The variance between the high -achieving chemistry map and the high-MPT map may be attributed to the reason that students who are proficient in math group those chemistry topics together because they require relatively more mathematics. The high-achieving chemistry map, on the other hand, could be portraying a structure that reveals overall proficiency in chemistry that requires mastery of both algorithmic and conceptual understanding (Teichert et al., 2020).

Following the same method utilized for the analysis of high- and low-achieving concept maps, the high- and low-MPT maps were investigated using the extended chemistry triplet (See Figure 4). In the High MPT map, as visualized in the high achieving chemistry concept map, there are distinct groups that are made up of terms with the same representational levels. On the right side of the map, there is a group of macroscopic terms with matter as the only macroscopic term on the left. Submicroscopic terms aggregate on the left side of the map. One dissimilarity is that symbolic terms, periodic trends, coordination chemistry, and stoichiometry, are not in close proximity with one another as exhibited in the high-achieving chemistry concept map, however, two of the symbolic terms, periodic trends and coordination chemistry, are in the same cluster. Process terms, reaction and equilibrium, are also within the same cluster. Moreover, similar to the high achieving chemistry map, those with high performance in mathematics cluster terms with the same classifications in the same areas of their knowledge structure.

Similar to the structure of low-achieving students in chemistry, in the low MPT map, it is difficult to visualize a clear pattern among the terms that are categorized in the same representational level. There is a vague pattern of macroscopic terms at the top of the structure, while the submicroscopic terms are roughly spread across the bottom left of the structure. The low performance of the students in these groups could be related to their inability of seeing the latent connections between these different terms that are mostly obvious to experts (Chi et al., 1981, 1988; Johnstone, 1991).

\section{Exploring Differences Between Male and Female Students' Concept Maps}

The third objective of our investigation was to provide a visual representation of how each gender organize information and insight into how gender affects concept map construction. Several studies (Boujaoude \& Attieh, 2008; Ezeudu, 2015; Gerstner \& Bogner, 2009; Williamson et al., 2020) reveal that females and males do organize concept maps differently. It was determined that females produce more complex maps than their male counterparts. Complexity was defined as the number of labeled net structures increased presence in each student's concept map based on Kinchin's coding schema (Heron et al., 2018). In these studies, in order to identify an overall trend, the analysis of individual concept maps was utilized with significant limitations.

However, this study, with the collective use of Image J, R, JPathfinder, and Gephi, enabled the examination of the concept maps of females and males on a group-level (see Figure 5) and capture the differences between them more effectively. In the male structure, there are four clusters, whereas in the female structure there are three clusters. The female cluster also has an isolated concept, change and the male cluster has no isolated concepts. Most terms are clustered the same way between both maps, and the terms that are not placed in the same cluster are change, coordination chemistry, and structure.

Upon analysis, it was noted that both genders place kinetics and energy within the same cluster as seen in the maps of high MPT and the low-achieving students in chemistry, which highlights the importance of distinguishing chemical kinetics from kinetic energy. Based on the visual inspection of the groupings of the terms on two maps, a slight variation was determined 


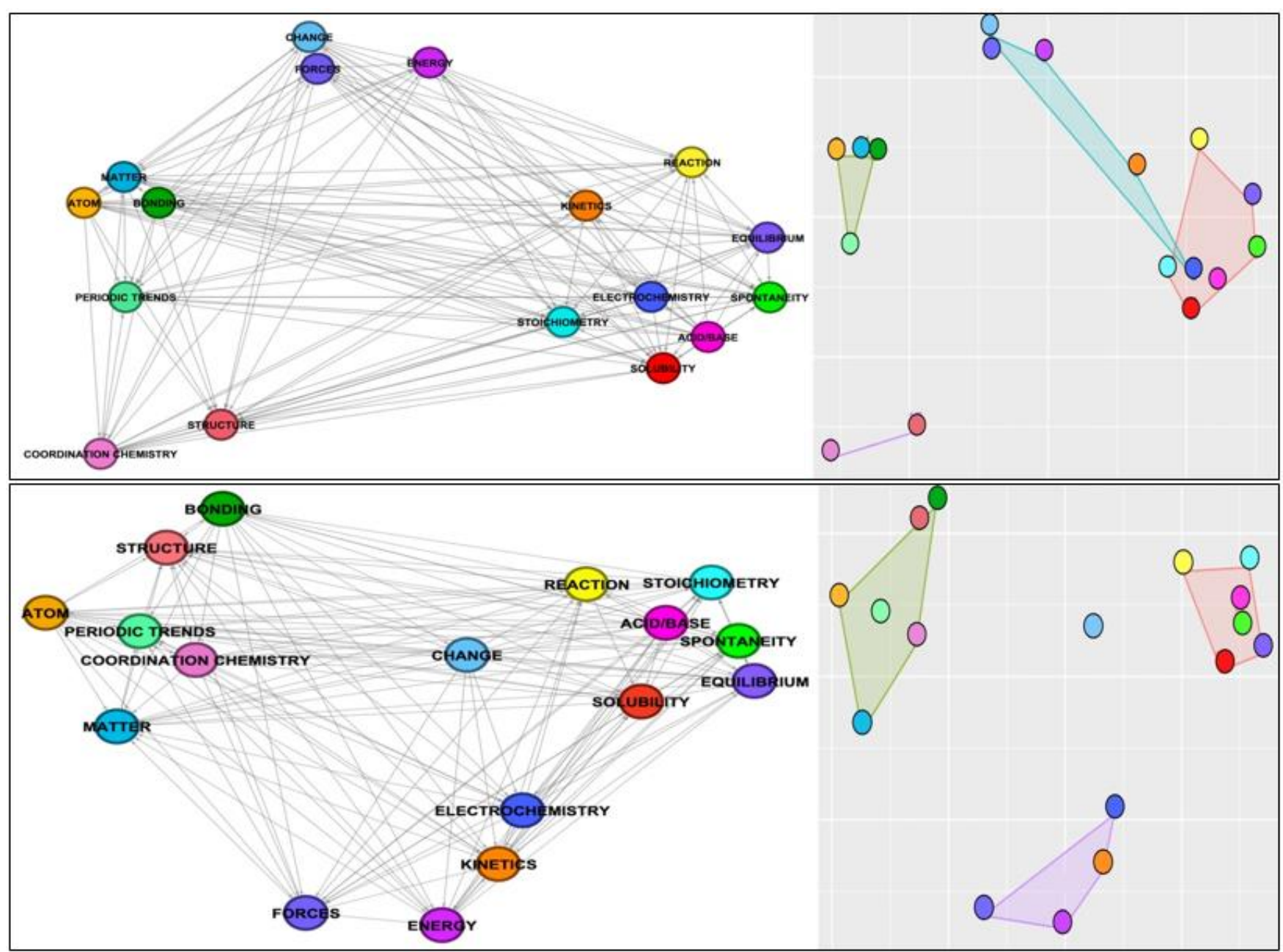

Figure 5. Knowledge structures of male (top) and female (bottom) students

between the chemistry knowledge structures of females and males. The eccentricity values as shown on Table 4 better illustrate the differences between each group.

The main difference is with which terms each gender considers as central. In the female map, the central concepts were bonding and structure, where the central concepts in the male map were change and energy which are terms that have large deviations from center in the female's knowledge structure. Also, it should be noted that in the female map, out of 17 terms, seven terms have an eccentricity value of ten or higher, while the highest eccentricity value in the male map is nine. The difference could be a sign for weak connections between the terms made by females. In addition, it could be speculated as females are in the process of reorganization of their knowledge pieces in creating a more complex structure (diSessa, 1988; Heron et al., 2018). This is a topic that needs further investigation.

Under the scope of extended chemistry triplet analysis (see Figure 6), within the female concept map, there is a distinct grouping of macroscopic terms at the right side of the structure with matter as the only macroscopic term on the left. Additionally, submicroscopic terms aggregate mostly towards the left of the graph with acid base as the only submicroscopic term on the right.

As for symbolic terms, those that are primarily symbolic only form a cluster between periodic trends and

Table 4. Eccentricity values of terms for female and male students

\begin{tabular}{|c|c|c|c|c|c|c|c|c|c|c|c|c|c|c|c|c|c|}
\hline & 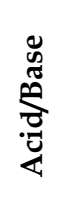 & $\underset{\Xi}{\stackrel{0}{*}}$ & 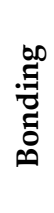 & 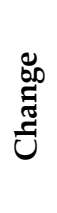 & 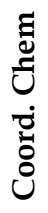 & 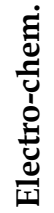 & 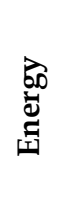 & 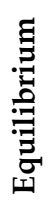 & 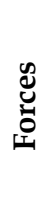 & 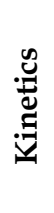 & 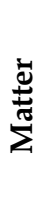 & 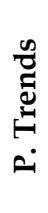 & 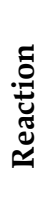 & 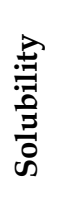 & 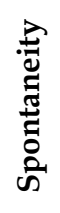 & 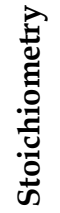 & D. \\
\hline$F$ & 10 & 7 & $6^{*}$ & 11 & 7 & 11 & 10 & 9 & 9 & 10 & 8 & 8 & 7 & 11 & 10 & 8 & $6^{*}$ \\
\hline $\mathrm{M}$ & 7 & 8 & 7 & $5^{*}$ & 9 & 9 & $5^{*}$ & 8 & 6 & 6 & 9 & 9 & 6 & 8 & 9 & 7 & 8 \\
\hline
\end{tabular}

* Central terms are indicated by an asterisk 

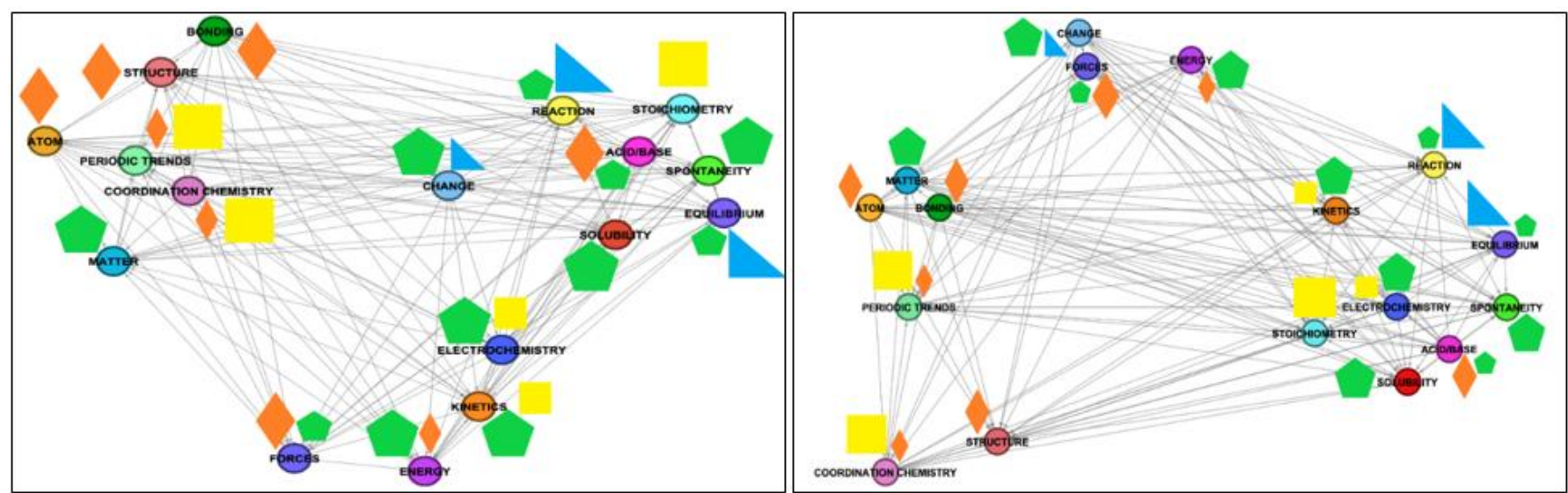

Figure 6. Knowledge structures with chemistry triplet of female (left) and male (right) students. Meaning of symbols: Pentagon-macroscopic, diamond-submicroscopic, square- symbolic, triangle- process

coordination chemistry and terms that are secondarily symbolic, kinetics and electrochemistry, also form a cluster. The symbolic term, stoichiometry, is on its own. The female concept map also exhibits distinct organization of terms as visualized in the high MPT and high achieving in chemistry maps. It should be noted, however, that females made up a majority of our participants (72\%). Therefore, those in this sample may have been mostly made up of high scoring individuals. The male map also exhibits a distinct pattern of macroscopic terms on the right side of the structure with matter as the only macroscopic term on the left. There is a clear cluster of submicroscopic terms on the left of the graph with acid base as the only submicroscopic term on the right. The primarily and secondarily symbolic terms, periodic trends, coordination chemistry, stoichiometry, and electrochemistry form two separate clusters. Additionally, process terms, reaction and equilibrium, are grouped together whereas change, which is secondarily classified as process, is on its own. Both genders tend to create their structures by placing terms of the same representational level in the same region. Moreover, observing the overall patterns of how each gender organizes each representational level of chemistry reveals similarities in the organization of their knowledge structures. These findings indicate that extended chemistry triplet could be added as a layer to bring depth to the analysis of chemistry concept maps (Gulacar et al., 2020).

\section{LIMITATIONS}

Although Gephi works as a useful medium to illustrate the relationships between concepts, due to the nature of Gephi treating each term as a magnet, the concept maps generated by Gephi itself do not represent accurately clusters that form in each groups' knowledge structures. Additionally, it is difficult to illustrate the 3D nature of these maps in this paper. In order to further determine how each group relates each term, the use of the $\mathrm{R}$ was required. Additionally, the structures generated by Gephi structures do not reveal central concepts and required JPathfinder to provide eccentricity values that illuminate the relationships between terms. While cluster analysis with $\mathrm{R}$ and eccentricity values with JPathfinder provide valuable insight into the hidden groupings on the maps, they are not always sufficient in fully explaining the trends and patterns observed in the maps of students with various achievement levels in chemistry, varying proficiencies in math, or different sexes.

Another limitation is that the population of students that participated in this study were majorly female $(72 \%$ female; $28 \%$ male). It is difficult to gauge how this influences how each map is generated. Therefore, for future studies it is important to obtain populations with relatively even distribution of females and males.

It is difficult to precisely assess the quality of each map without an expert map as a reference. Without an expert comparison, there is no way to accurately evaluate the correctness of the relationships within each cluster. The interpretation of the relationships of terms in this study were only based on existing literature. Moreover, the creation of an expert map with the method utilized in this study can provide researchers an ideal referent map that would be essential to provide a robust understanding of how students' conceptualization of chemistry occurs.

\section{CONCLUSIONS}

In this study, the primary goal was to propose a methodology to refine concept map analysis, create an effective assessment tool, and find an efficient means to evaluate how students relate chemistry topics they learn to the representational levels in chemistry. This study utilized a method that synthesizes $R$ with Gephi to create representative maps. The use of $R$ to evaluate clusters within each map provide researchers an objective method to determine how the terms are related with one another without potential bias. The representative maps generated in this study provide researchers the ability to 
evaluate an overall group's understanding of topics and evolution of knowledge structures (Gulacar et al., 2020) without having to assess each concept map individually. As a result, researchers could more easily extrapolate findings and draw conclusions.

This study also illustrates the importance of eccentricity values as another dimension of concept map analysis because they can reveal central concepts that can provide hints on how each group constructs their chemistry knowledge structure. Although the role of central concepts has not been widely studied, they can be thought of cementing underlying principles providing foundation to students' understanding of related topics. The central concepts could especially be important if the evolution of students' knowledge structures is explored over few semesters or years. They could be also compared for the students who are majoring in different fields at upper levels. This analysis was not done in this study because the majority of the participants were freshmen, and it is suspected that they have not gained the true identity of their majors yet (Meijers, 1998).

While the use of eccentricity values and clusters determined by the $\mathrm{R}$ reveals interesting differences between the groups examined in the study, they were limited in explaining fully why they form the clusters in the way that they construct. Here, the idea of chemistry triplet (Johnstone, 1991), the connection of the three representational levels, submicroscopic, macroscopic, symbolic, and its extension, process (Dori \& Hameiri, 2003), was introduced and utilized to examine the representative concept maps. This analysis enabled to obtain answers regarding how each group organizes their knowledge and reveal one of the important variables determining the formation of clusters. This dimension should be considered by both teachers and researchers in the analysis of any concept map generated in chemistry classrooms. This way, teachers can determine how their high-achieving students differ from their low-achieving students in terms of mental construction of topics and modify the curriculum to promote the connections between different representational levels.

Despite several differences in the maps of high-MPT and high-achieving students in chemistry, it was noted that both maps have clear chemistry triplet patterns, which are mostly aligned with the clusters determined with R. Although the chemistry triplet is a more appropriate dimension for chemistry concept maps, the remaining tools and methods could easily be used in any field to generate representative concept maps and reveal potential misconceptions, which could be interpreted as misconnections (Kohn et al., 2018; Smith et al., 1994).

It is believed that a misconception related to chemical kinetics was captured in this study. In multiple maps (female, male, high-MPT, low-achieving in chemistry), there was a common trend of relating kinetics to energy more than thermodynamics or equilibrium while in most cases these topics are introduced as interdependent topics. This association between kinetics and energy could also be because students relate them to each other based on their superficial elements (Chi et al., 1981).

For the female and male maps, the eccentricity values revealed greater differences between concept maps than the cluster analysis initially revealed, which highlights the usefulness of eccentricity values for further analysis.

Exploring individual groups and comparing them to each other are useful methods to have more insight into performance differences between the student groups in the courses. However, there is a great need for the identification of representative expert concept maps by using the same terms, tools, and methods. These maps could be used as ideal maps or standards in these types of comparisons. In another future study, to better understand the role of gender in creating concept maps, first females and males should be categorized as highand low-achievers in chemistry and mathematics. Then, their concept maps should be analyzed to determine whether the performance in those courses or the gender is a more important factor influencing the concept maps. While this study focused on chemistry concept maps, the method used in this study can be utilized to assess concept map from other subjects and aid educators and researchers from any disciplines.

Author contributions: All authors have sufficiently contributed to the study, and agreed with the results and conclusions.

Funding: No funding source is reported for this study.

Declaration of interest: No conflict of interest is declared by authors.

\section{REFERENCES}

Ambrose, S. A., Bridges, M., DiPietro, M., Lovett, M., \& Norman, M. (2010). How learning works: Seven research-based principles for smart teaching. JosseyBass.

Andrews, M. H., \& Andrews, L. (1979). First-year chemistry grades and SAT math scores. Journal of Chemical Education, 56(4), 231-232. https:/ / doi.org/ 10.1021/ed056p231

Bada, S. O. (2015). Constructivism learning theory: A paradigm for teaching and learning. IOSR Journal of Research $\mathcal{E}$ Method in Education, 5(6), 66-70. https:/ / doi.org/10.9790/7388-05616670

Becker, N., Stanford, C., Towns, M., \& Cole, R. (2015). Translating across macroscopic, submicroscopic, and symbolic levels: the role of instructor facilitation in an inquiry-oriented physical chemistry class. Chemistry Education Research and Practice, 16(4), 769-785. https://doi.org/10.1039/ c5rp00064E 
Boujaoude, S., \& Attieh, M. (2008). The effect of using concept maps as study tools on achievement in chemistry. EURASIA Journal of Mathematics, Science $\mathcal{E}$ Technology Education, 4(3), 233. https://doi.org/ 10.12973 / ejmste/ 75345

Burrows, N. L., \& Mooring, S. R. (2015). Using concept mapping to uncover students' knowledge structures of chemical bonding concepts. Chemistry Education Research and Practice, 16(1), 53-66. https: / / doi.org/10.1039/c4rp00180j

Caine, G., \& Caine, R. N. (2006). Meaningful learning and the executive functions of the brain. New Directions for Adult and Continuing Education, 2006(110), 53-61. https://doi.org/10.1002/ace.219

Chi, M. T. H., Feltovich, P. J., \& Glaser, R. (1981). Categorization and representation of physics problems by experts and novices. Cognitive Science, 5(2), 121-152. https://doi.org/10.1207/ s15516709cog0502_2

Chi, M. T. H., Glaser, R., \& Farr, M. J. (1988). The nature of expertise. Lawrence Erlbaum. https:// doi.org/10.1038/332441a0

Cohen, R., \& Kelly, A. M. (2019). Community college chemistry coursetaking and STEM academic persistence. Journal of Chemical Education, 96(1), 311. https://doi.org/10.1021/acs.jchemed.8b00586

Coll, R., Ali, S., Bonato, J., \& Rohindra, D. (2006). Investigating first-year chemistry learning difficulties in the South Pacific: A case study from Fiji. International Journal of Science and Mathematics Education, 4(3), 365-390. https://doi.org/10.1007/ s10763-005-9007-6

Cotes, S., \& Cotuá, J. (2014). Using audience response systems during interactive lectures to promote active learning and conceptual understanding of stoichiometry. Journal of Chemical Education, 91(5), 673. https:/ / doi.org/10.1021/ed400111m

de Astudillo, L. R., \& Niaz, M. (1996). Reasoning strategies used by students to solve stoichiometry problems and its relationship to alternative conceptions, prior knowledge, and cognitive variables. Journal of Science Education and Technology, 5(2), 131-140. https:/ / doi.org/10.1007/ bf01575153

diSessa, A. A. (1988). Knowledge in pieces. In G. Forman, P. B. Pufall, G. Forman, \& P. B. Pufall (Eds.), Constructivism in the computer age. (pp. 49-70). Lawrence Erlbaum Associates, Inc.

Dori, Y. J., \& Hameiri, M. (2003). Multidimensional analysis system for quantitative chemistry problems: Symbol, macro, micro, and process aspects. Journal of Research in Science Teaching, 40(3), 278-302. https:/ / doi.org/10.1002/tea.10077

Dori, Y. J., \& Sasson, I. (2008). Chemical understanding and graphing skills in an honors case-based computerized chemistry laboratory environment: The value of bidirectional visual and textual representations. Journal of Research in Science Teaching, 45(2), 219-250. https://doi.org/10.1002/ tea.20197

Earl, B. L. (2007). Concept maps for general chemistry. Journal of Chemical Education, 84(11), 1788-1789. https:/ / doi.org/10.1021/ed084p1788

Ekmekci, A., Sahin, A., Gulacar, O., \& Almus, K. (2018). High school students' semantic networks of scientific method in an international science Olympiad context. Eurasia Journal of Mathematics, Science and Technology Education, 14(10), em1604. https:/ / doi.org/10.29333/ ejmste/93677

Ezeudu, F. O. (2015). A SWOT analysis of male and female students' performance in chemistry: A comparative study. Journal of Education and Practice, 6(28), 53-60.

Gadner, J., \& Ohnesorge, D. (2004). Conceptual knowledge organisation and the problem of understanding. In J. Gadner, R. Buber, \& L. Richards (Eds.), Organising knowledge: Methods and case studies (pp. 60-74). Palgrave Macmillan UK. https:/ / doi.org/10.1057/9780230523111_4

Gerstner, S., \& Bogner, F. X. (2009). Concept map structure, gender and teaching methods: An investigation of students' science learning. Educational Research, 51(4), 425-438. https:/ / doi.org/10.1080/00131880903354758

Gulacar, O., Eilks, I., \& Bowman, C. R. (2014). Differences in general cognitive abilities and domain-specific skills of higher- and lower-achieving students in stoichiometry. Journal of Chemical Education, 91(7), 961-968. https:/ / doi.org/10.1021/ed400894b

Gulacar, O., Milkey, A., \& Eilks, I. (2020). Exploring cluster changes in students' knowledge structures throughout general chemistry. Eurasia Journal of Mathematics, Science and Technology Education, 16(6), em1850. https:/ / doi.org/10.29333/ ejmste/7860

Gulacar, O., Milkey, A., \& McLane, S. (2019). Exploring the effect of prior knowledge and gender on undergraduate students' knowledge structures in chemistry. Eurasia Journal of Mathematics, Science and Technology Education, 15(8), em1726. https:// doi.org/10.29333/ejmste/106231

Gulacar, O., Sinan, O., Bowman, C., \& Yildirim, Y. (2015). Exploring the changes in students' understanding of the scientific method using word associations. Research in Science Education, 45(5), 717-726. https:/ / doi.org/10.1007/s11165-014-9443-9

Heron, M., Kinchin, I. M., \& Medland, E. (2018). Interview talk and the co-construction of concept maps. Educational Research, 60(4), 373-389. https:/ / doi.org/10.1080/00131881.2018.1522963 
Johnston, P. R., Watters, D. J., Brown, C. L., \& Loughlin, W. A. (2016). An investigation into student perceptions towards mathematics and their performance in first year chemistry: Introduction of online maths skills support. Chemistry Education Research and Practice, 17(4), 1203-1214. https://doi.org/10.1039/C6RP00175K

Johnstone, A. H. (1991). Why is science difficult to learn? Things are seldom what they seem. Journal of Computer Assisted Learning, 7(2), 75-83. https:// doi.org/10.1111/j.1365-2729.1991.tb00230.x

Kaya, O. (2008). A student-centred approach: Assessing the changes in pospective science teachers' conceptual understanding by concept mapping in a general chemistry laboratory. Research in Science Education, 38(1), 91-110. https://doi.org/10.1007/ s11165-007-9048-7

Kibar, Z. B., Yaman, F., \& Ayas, A. (2013). Assessing prospective chemistry teachers' understanding of gases through qualitative and quantitative analyses of their concept maps. Chemistry Education Research and Practice, 14(4), 542-554. https://doi.org/ 10.1039/C3RP00052D

Kodali, T. (2016). Hierarchical clustering in $R$. https: / / www.r-bloggers.com/hierarchicalclustering-in-r-2/

Kohn, K. P., Underwood, S. M., \& Cooper, M. M. (2018). Energy connections and misconnections across chemistry and biology. CBE Life Sciences Education, 17(1), Article 3. https:/ / doi.org/10.1187/ cbe.17-080169

Krabbe, H. (2014). Digital concept mapping for formative assessment. In D. Ifenthaler, \& R. Hanewald (Eds.), Digital knowledge maps in education: Technologyenhanced support for teachers and learners (pp. 275297). Springer New York + Business Media. https://doi.org/10.1007/978-1-4614-3178-7_15

Kruskal, J. B., \& Wish, M. (1978). Multidimensional scaling. Sage Publications. https://doi.org/10.4135/ 9781412985130

Luxford, C. J., \& Bretz, S. L. (2014). Development of the bonding representations inventory to identify student misconceptions about covalent and ionic bonding representations. Journal of Chemical Education, 91(3), 312-320. https:/ / doi.org/10.1021/ ed400700q

Luxford, C. J., \& Holme, T. A. (2015). What do conceptual holes in assessment say about the topics we teach in general chemistry? Journal of Chemical Education, 92(6), 993. https:/ / doi.org/10.1021/ed500889j

Meijers, F. (1998). The development of a career identity. International Journal for the Advancement of Counselling, 20(3), 191-207. https://doi.org/ 10.1023/A:1005399417256
Murphy, K., Holme, T., Zenisky, A., Carithers, H., \& Knaus, K. (2012). Building the ACS exams anchoring concept content map for undergraduate chemistry. Journal of Chemical Education, 89(6), 715720. https:/ / doi.org/10.1021/ed300049w

Neiles, K. Y. (2014). Measuring knowledge: Tools to measure students' mental organization of chemistry information. ACS Symposium Series, 1166, 169-190. https://doi.org/10.1021/bk-2014-1166. ch010

Nicoll, G., Francisco, J., \& Nakhleh, M. B. (2001). An investigation of the value of using concept maps in general chemistry. Journal of Chemical Education, 78(8), 1111. https:/ / doi.org/10.1021/ED078P1111

Ørom, A. (2003). Knowledge organization in the domain of art studies - history, transition and conceptual changes. Knowledge Organization, 30(3), 128-143. https:/ / doi.org/10.5771/0943-7444-2008-2-3-86

Paideya, V., \& Sookrajh, R. (2010). Exploring the use of supplemental instruction: Supporting deep understanding and higher-order thinking in chemistry. South African Journal of Higher Education, 24(5), 758-770.

Pirnay-Dummer, P. (2014). Gainfully guided misconception. In D. Ifenthaler, \& R. Hanewald (Eds.), Digital knowledge maps in education: Technology-enhanced support for teachers and learners (pp. 253-273). Springer New York. https:/ / doi.org/10.1007/978-1-4614-3178-7_14

Pólya, G. (1945). How to solve it a new aspect of mathematical method. Princeton University Press. https:/ / doi.org/10.1515/9781400828678

Preininger, A. (2017). Embedded mathematics in chemistry: A case study of students' attitudes and mastery. Journal of Science Education and Technology, 26(1), 58-69. https://doi.org/10.1007/s10956-0169651-3

Ralph, V. R., \& Lewis, S. E. (2018). Chemistry topics posing incommensurate difficulty to students with low math aptitude scores. Chemistry Education Research and Practice, 19(3), 867-884. https:/ / doi.org/10.1039/c8rp00115d

Schreiber, D. A., \& Abbeg, G. L. (1991). Scoring studentgenerated concept maps in introductory college chemistry. Paper prepared for The National Association for Research in Science Teaching Annual Meeting, Lake Geneva, WI.

Sharara, H. (2011). How structural assessment of knowledge can be used for the identification of specific alternative conceptions and for assessing domain competence in physics [M.A. thesis, University of Ottawa].

Smith, G. A., \& Bermea, S. B. (2012). Using students' sketches to recognize alternative conceptions about plate tectonics persisting from prior instruction. 
Journal of Geoscience Education, 60(4), 350-359. https:// doi.org/10.5408/11-251.1

Smith, J. P., diSessa, A. A., \& Roschelle, J. (1994) Misconceptions reconceived: A constructivist analysis of knowledge in transition. The Journal of the Learning Sciences, 3(2), 115-163. https://doi.org/10.1207/s15327809jls0302_1

Taber, K. S. (2013). Revisiting the chemistry triplet: Drawing upon the nature of chemical knowledge and the psychology of learning to inform chemistry education. Chemistry Education Research and Practice, 14(2), 156-168. https://doi.org/10.1039/C3RP00 012E

Tait, H., \& Entwistle, N. (1996). Identifying students at risk through ineffective study strategies. Higher Education, 31(1), 97-116. https://doi.org/10.1007/ BF00129109

Talanquer, V. (2011a). Macro, submicro, and symbolic: The many faces of the chemistry "triplet". International Journal of Science Education, 33(2), 179195. https:/ / doi.org/10.1080/09500690903386435

Talbert, L. E., Bonner, J., Mortezaei, K., Guregyan, C., Henbest, G., \& Eichler, J. F. (2020). Revisiting the use of concept maps in a large enrollment general chemistry course: implementation and assessment. Chemistry Education Research and Practice, 21(1), 3750. https:// doi.org/10.1039/c9rp00059C

Teichert, M. A., Schroeder, M. J., Lin, S., Dillner, D. K., Komperda, R., \& Bunce, D. M. (2020). Problemsolving behaviors of different achievement groups on multiple-choice questions in general chemistry. Journal of Chemical Education, 97(1), 3-15. https://doi.org/10.1021/acs.jchemed.9b00774

Trumpower, D. L., Filiz, M., \& Sarwar, G. S. (2014). Assessment for learning using digital knowledge maps. In D. Ifenthaler, \& R. Hanewald (Eds.), Digital knowledge maps in education: Technologyenhanced support for teachers and learners (pp. 221237). Springer New York. https:// doi.org/10.1007 /978-1-4614-3178-7_12

van Kesteren, M. T. R., Krabbendam, L., \& Meeter, M. (2018). Integrating educational knowledge: reactivation of prior knowledge during educational learning enhances memory integration. NPJ Science of Learning, 3(11), 1-8. https://doi.org/10.1038/ s41539-018-0027-8

Van Zele, E., Lenaerts, J., \& Wieme, W. (2004). Improving the usefulness of concept maps as a research tool for science education. International Journal of Science Education, 26(9), 1043-1064. https://doi.org/ $10.1080 / 1468181032000158336$

Von Der Heidt, T. (2015). Concept maps for assessing change in learning: a study of undergraduate business students in first-year marketing in China. Assessment \& Evaluation in Higher Education, 40(2), 286-308.

https:/ / doi.org/10.1080/02602938.2014.910637

Vrabec, M., \& Prokša, M. (2016). Identifying misconceptions related to chemical bonding concepts in the Slovak school system using the bonding representations inventory as a diagnostic tool. Journal of Chemical Education, 93(8), 1364-1370. https:// doi.org/10.1021/acs.jchemed.5b00953

Williamson, V. M., Walker, D. R., Chuu, E., Broadway, S., Mamiya, B., Powell, C. B., Shelton, G. R., Weber, R., Dabney, A. R., \& Mason, D. (2020). Impact of basic arithmetic skills on success in first-semester general chemistry. Chemistry Education Research and Practice, 21(1), 51-61. https://doi.org/10.1039/ c9rp00077a

Wilson, J. (1996). Concept maps about chemical equilibrium and students' achievement scores. Research in Science Education, 26(2), 169-185. https:/ / doi.org/10.1007/BF02356430

Yaman, F., \& Ayas, A. (2015). Assessing changes in high school students' conceptual understanding through concept maps before and after the Computer-Based Predict-Observe-Explain (CBPOE) tasks on acid-base chemistry at the secondary level. Chemistry Education Research and Practice, 16(4), 843. https:// doi.org/10.1039/C5RP00088B

Yeh, Y.-C. (2004). Seventh graders' academic achievement, creativity, and ability to construct a cross-domain concept map-A brain function perspective. The Journal of Creative Behavior, 38(2), 125. https:// doi.org/10.1002/j.2162-6057.2004.tb0 1236.x

\section{http://www.ejmste.com}

